\title{
Avaliação do ambiente de trabalho na propagação de Eucalyptus spp. ${ }^{1}$
}

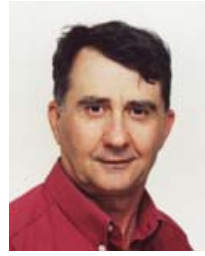

José U. Alves ${ }^{2}$, Luciano J. Minetti ${ }^{3}$, Amaury P. de Souza ${ }^{3}$, Kátia R. Silva² José M. Gomes ${ }^{4}$ \& Nilton C. Fiedler ${ }^{4}$

\footnotetext{
1 Trabalho de pesquisa desenvolvido com recursos financeiros da Fundação de Amparo à Pesquisa do Estado de Minas Gerais - FAPEMIG

2 Depto. de Engenharia Florestal/UFV. Fone: (31) 3899-2466 E-mail: ms31053@correio.ufv.br e krsilva@alunos.ufv.br

${ }^{3}$ Depto. de Engenharia Florestal/UFV. Fone: (31) 3899-2466. E-mail: minetti@ufv.br e amaurysouza@ufv.br (Foto)

${ }^{4}$ Depto. de Engenharia Florestal/UnB. Fone: (61) 307-2700. E-mail: fiedler@unb.br
}

Protocolo $99-28 / 6 / 2001$

\begin{abstract}
Resumo: Nesta pesquisa, desenvolvida a partir de dados coletados em viveiro florestal no Vale do Rio Doce, MG, objetivou-se estudar os fatores ergonômicos relacionados às atividades exercidas nesses ambientes, visando à melhoria da saúde, do bem-estar, da segurança, do conforto e da produtividade dos trabalhadores. O objetivo específico foi a caracterização do ambiente de trabalho em relação ao conforto térmico, luminosidade e ruído. Os dados foram coletados através de medições do clima do local de trabalho, da luminosidade e do ruído. Os resultados indicaram que o ambiente de trabalho apresentou valores do Índice de Bulbo Úmido Termômetro de Globo, nas casas-de-vegetação, acima dos limites. A luminosidade encontrada foi considerada insuficiente nos postos de trabalho das atividades de estaqueamento e corte de macroestacas. Os níveis de ruído encontrados foram elevados nas atividades de lavagem e desinfecção de tubetes.
\end{abstract}

Palavras-chave: propagação de planta, ergonomia, fatores ambientais

\section{Evaluation of the working ambient during propagation of Eucalyptus spp.}

\begin{abstract}
The study reported here was conducted with data collected in a forest nursery in Vale do Rio Doce, Minas Gerais State-Brazil, with the objective of evaluating the ergonomic factors related to the activities carried out at this place, considering the various aspects like health, welfare, safety, comfort and productivity of the workers. The specific objective was the characterization of the working ambient in relation to the thermal comfort, light and noise. Data were collected about temperature, light and noise at the work posts. The results indicated that the ambient presented index values of the Moist Bulb Globe Thermometer above the limits in the green houses. The light was considered insufficient at the work post for the activities such as staking and macro cuttings. The noise levels were high in the areas where the activities of washing and disinfecting of tubes were being carried out.
\end{abstract}

Key words: plant propagation, ergonomy, environmental factors

\section{INTRODUÇÃO}

Em análises ergonômicas considera-se o meio físico no qual se efetua um trabalho. O ruído, as vibrações, o calor, o frio, a altitude, os produtos tóxicos etc., quando excedem certos limites podem provocar doenças ou alterar o bem-estar (Apud, 1997). Situações envolvendo esses fatores são comuns nas atividades de propagação de plantas, merecendo estudos para quantificar seus níveis, melhorando o ambiente de trabalho nessa área florestal.

Nas operações de propagação de plantas em viveiros, o trabalho é efetuado sob várias condições adversas ao bem- estar, à segurança e à saúde do ser humano. Durante toda a jornada de trabalho o operário pode encontrar-se sujeito a níveis de ruídos elevados, variações de temperatura e iluminação inadequada, entre outros fatores.

O trabalho em condições climáticas desfavoráveis produz fadiga, extenuação física e nervosa, diminuição do rendimento e aumento nos erros e riscos de acidentes no trabalho, além de expor o organismo a diversas doenças (Couto, 1987).

$\mathrm{Na}$ análise do clima é importante verificar se a situação se enquadra como problema de conforto ou de sobrecarga térmica. A zona de conforto térmico é delimitada pelas temperaturas entre 20 e $24^{\circ} \mathrm{C}$, com umidade relativa de 40 a $60 \%$ e velocidade 
do ar moderada da ordem de $0,7 \mathrm{~m} \mathrm{~s}^{-1}$. As diferenças de temperaturas presentes no mesmo ambiente não devem ser superiores a $4{ }^{\circ} \mathrm{C}$, sendo que acima de $30^{\circ} \mathrm{C}$ se aumenta o risco de danos à saúde do operador, as pausas se tornam maiores e mais freqüentes, o grau de concentração diminui e a freqüência de erros e acidentes tende a aumentar significativamente (Iida, 1990); já a sobrecarga térmica varia de atividade para atividade, em função da atividade metabólica e do esforço físico envolvido no trabalho.

A avaliação da exposição à temperaturas excessivas é de grande importância para que se possa garantir o conforto térmico do trabalhador. Existem vários índices para avaliação da exposição ao calor, dentre os quais se destacam os Índice de Temperatura Efetiva Corrigida, Índice de Sobrecarga Térmica, Índice do Termômetro de Globo Úmido, Índice de Bulbo Úmido e o Termômetro de Globo (IBUTG); no entanto, a Norma Regulamentadora (NR) 15 - Anexo 3 (Segurança e medicina do trabalho, 1998), prescreve o uso do IBUTG para avaliação da exposição ao calor.

O IBUTG funciona como um indicador que engloba os principais fatores causadores da sobrecarga térmica (alta temperatura, metabolismo, calor radiante e alta umidade relativa do ar) e, também, os principais fatores atenuadores da mesma (ventilação do ambiente, baixa umidade relativa do ar e baixa temperatura) fornecendo uma escala de tempo de trabalho e de tempo de repouso para aquela situação (Couto, 1995).

$\mathrm{O}$ aparelho visual fornece informação sensitiva extremamente precisa sendo, no entanto, o grau de iluminação muito importante na apreensão do que se vê. Desta forma, uma luz apropriada é necessidade primordial em qualquer local de trabalho. Não basta a intensidade adequada de luz; é essencial, também, que exista um contraste luminoso entre o visor e o pano de fundo, com ausência completa de qualquer brilho que ofusque (Iida,1990). Portanto, uma iluminação adequada do ambiente de trabalho é essencial para evitar problemas como fadiga visual, incidência de erros, queda no rendimento e acidentes.

O fator mais relevante a ser considerado no estudo da iluminação para tarefas humanas é a determinação da relação entre o nível ideal de iluminação e o tipo de trabalho, isto é, qual é a quantidade de luz de que se deve dispor para a realização da tarefa, obtendo-se o máximo rendimento e conforto do operador (Iida \& Wierzzbicki, 1978).

As repercussões comprovadas de iluminação deficiente caracterizam o quadro de fadiga visual. Quando um objeto não estiver sendo adequadamente visualizado, isto pode ser devido a um tamanho muito pequeno para aquela distância, à uma iluminação deficiente, a um contraste inadequado dos seus limites, a uma diferença importante de brilho no campo visual ou, ainda, a um tempo insuficiente para sua focalização adequada (Couto, 1987).

O ruído é um som ou uma mistura complexa de sons, que causa sensação de desconforto, medida numa escala logarítmica, em uma unidade chamada decibel $(\mathrm{dB})$ que afeta, física e psicologicamente, a pessoa exposta, causando-lhe lesões irreversíveis (Grandjean, 1981; Iida, 1990).

O ruído é um inimigo subliminar e perigoso. Um trabalhador que aparentemente possui boa saúde, pode estar sendo vítima do seu ataque. Como o ser humano tem alta capacidade de adaptação a ambientes adversos, pode ocorrer o desenvolvimento de um estado de fadiga e fuga de energia, sem que o trabalhador se dê conta (Minette, 1996).

A permanência em locais de trabalho que apresentam níveis de ruído de 85 a $90 \mathrm{~dB}$ oferece grande risco, que se acentua em dependência da freqüência dos sons e do tempo de permanência nessa situação (Alves et al.,1997). A exposição, por um tempo superior a $5 \mathrm{~h}$ a ruídos que atinjam $110 \mathrm{~dB}$, tem conseqüências bastante graves; já a $160 \mathrm{~dB}$, ocorre surdez imediata e irreversível (Verdussen, 1978).

De acordo com Edholm (1968) o ruído constitui problema por razões primordiais: pode perturbar e interferir no trabalho e, ainda, causar a surdez. Verdussen (1978) cita que os efeitos nocivos do ruído sobre o homem podem ser divididos em fisiológicos e psicológicos. E, ainda segundo Máscia et al. (1989) a presença de ruído prejudica o desempenho, perturba as relações interindividuais, diminui as possibilidades de fixação e concentração, comprometendo as atividades psicomotoras.

De acordo com as normas brasileiras, a máxima exposição diária permissível sem protetor auricular, é de $85 \mathrm{~dB}$. Exposições superiores são permitidas, desde que, para cada aumento de $5 \mathrm{~dB}$ no nível do ruído, o tempo de exposição seja reduzido pela metade (Atlas, 1985, citado por Souza, 1993).

O objetivo desta pesquisa foi estudar os fatores ergonômicos relacionados com a caracterização do ambiente de trabalho (conforto térmico, luminosidade e ruído) em viveiros de propagação de plantas na região do Vale do Rio Doce, $\mathrm{MG}$, visando à melhoria da saúde, do bem-estar, da segurança, do conforto e da produtividade dos trabalhadores nesta área florestal.

\section{MATERIAL E MÉTODOS}

Este trabalho foi desenvolvido com dados coletados em áreas de viveiros florestais, no vale do Rio Doce, em Minas Gerais.

A jornada de trabalho na empresa tinha duração de $8 \mathrm{~h}$ e $30 \mathrm{~min}$, no período de segunda a sexta-feira, iniciando-se às $7 \mathrm{e}$ finalizando às $16 \mathrm{~h}$ e $30 \mathrm{~min}$. $\mathrm{O}$ intervalo para o almoço era de $1 \mathrm{~h}$, entre $11 \mathrm{e} 12 \mathrm{~h}$.

O viveiro produzia mudas de Eucalyptus spp. para a constituição de plantios da própria empresa, pesquisas e vendas a terceiros. A produção anual de mudas era aproximadamente de 8.800 .000 mudas, e por dia eram estaqueadas em torno de 100.000 estacas.

As mudas eram produzidas em tubetes plásticos com substrato formado por uma mistura de vermiculita, palha de arroz carbonizada, composto orgânico e adubo químico composto por nitrogênio, fósforo e potássio (NPK) e micronutrientes.

\section{Caracterização dos fatores do ambiente de trabalho}

Clima no local de trabalho: O clima no local de trabalho foi avaliado por meio do termômetro digital da marca Wibget, modelo RSS-214, considerando-se ambientes internos (sem carga solar) e externos (com carga solar). O aparelho foi instalado nos diversos ambientes encontrados na propagação de plantas e as leituras foram realizadas em intervalo de $2 \mathrm{~h}$, durante toda a jornada de trabalho, iniciando-se às $7 \mathrm{~h} \mathrm{e}$ finalizando às $17 \mathrm{~h}$. 
O índice de bulbo úmido - termômetro de globo (IBUTG), é definido pelas equações descritas a seguir, considerando-se os ambientes internos ou externos, sem carga solar, e ambientes externos com carga solar (Segurança e medicina do trabalho, 1998):

a) Ambientes internos ou externos sem carga solar:

$$
\mathrm{IBUTG}=0,7 \mathrm{tbn}+0,3 \mathrm{tg}
$$

b) Ambientes externos com carga solar:

$$
\mathrm{IBUTG}=0,7 \mathrm{tbn}+0,1 \mathrm{tbs}+0,2 \mathrm{tg}
$$

em que:

tbn - temperatura de bulbo úmido natural, ${ }^{\circ} \mathrm{C}$

tg - temperatura de globo, ${ }^{\circ} \mathrm{C}$

tbs - temperatura de bulbo seco, ${ }^{\circ} \mathrm{C}$

Os limites toleráveis para a exposição ao calor foram estabelecidos de acordo com a Legislação Brasileira de Atividades e Operações Insalubre (Segurança e medicina do trabalho, 1998) conforme a Tabela 1.

$\mathrm{Na}$ determinação do consumo energético da atividade, para o critério do IBUTG é levada em consideração a carga de trabalho físico do trabalhador. Os valores estimados da taxa de metabolismo, em razão da atividade exercida pelo operador e de acordo com a NR 15 anexo $n^{\circ} 3$ (Segurança e medicina do trabalho, 1998), são mostrados na Tabela 2.

Luminosidade no local de trabalho: A avaliação da luminosidade foi feita no campo de trabalho, utilizando-se de um luxímetro digital com fotocélula, da marca Lutron LX-101 entendendose, como campo de trabalho, os locais onde eram realizadas as diversas atividades da propagação de plantas. As leituras foram realizadas no decorrer do dia, de $2 \mathrm{em} 2 \mathrm{~h}$, iniciando-se às $7 \mathrm{com}$ término às $15 \mathrm{~h}$. $\mathrm{O}$ aparelho foi posicionado num plano horizontal, onde eram feitas as diversas atividades, obtendose a leitura em lux.

Ruído no local de trabalho: Nesse estudo, avaliou-se o nível de ruído com um decibelímetro e um dosímetro da marca Bruel e Kjaer, sendo que o decibelímetro foi usado para medições de doses instantâneas de ruído e o dosímetro para avaliar a dose média de ruído recebida durante a jornada de trabalho.

\section{RESULTADOS E DISCUSSÃO}

\section{Fatores ambientais}

Clima do local de trabalho: $O$ índice IBUTG adotado pela legislação brasileira para determinar os limites de tolerância,
Tabela 2. Estimativa das taxas de metabolismo por tipo de

\begin{tabular}{|c|c|}
\hline Tipo de Atividade & $\mathrm{kcal} \mathrm{h}^{-1}$ \\
\hline Sentado em Repouso & 100 \\
\hline \multicolumn{2}{|l|}{ Trabalho Leve } \\
\hline $\begin{array}{l}\text { Sentado, movimento moderado com os braços e o tronco } \\
\text { (Ex.: datilografia) }\end{array}$ & 125 \\
\hline $\begin{array}{l}\text { Sentado, movimento moderado com os braços e as pernas } \\
\text { (Ex.:dirigir) }\end{array}$ & 150 \\
\hline $\begin{array}{l}\text { De pé, trabalho leve, em máquinas ou em bancada, } \\
\text { principalmente com os braços }\end{array}$ & 150 \\
\hline \multicolumn{2}{|l|}{ Trabalho Moderado } \\
\hline $\begin{array}{l}\text { Sentado, movimentos vigorosos com os braços } \\
\text { e as pernas }\end{array}$ & 180 \\
\hline $\begin{array}{l}\text { De pé, trabalho leve em máquinas ou bancada, } \\
\text { com alguma movimentação }\end{array}$ & 175 \\
\hline $\begin{array}{l}\text { De pé, trabalho moderado em máquinas ou bancada, } \\
\text { com algum movimento }\end{array}$ & 220 \\
\hline $\begin{array}{l}\text { Em movimento, trabalho moderado de levantar } \\
\text { e empurrar }\end{array}$ & 300 \\
\hline \multicolumn{2}{|l|}{ Trabalho Pesado } \\
\hline $\begin{array}{l}\text { Trabalho intermitente de levantar, empurrar ou arrastar } \\
\text { pesos (Ex.: remoção com pá) }\end{array}$ & 440 \\
\hline Trabalhos fatigantes & 550 \\
\hline
\end{tabular}
atividade

baseia-se no estabelecimento de determinado valor, abaixo do qual haverá pouca possibilidade de danos à saúde do trabalhador e, acima dele, essa chance se torna maior (Couto, 1987). Segundo Couto (1996) as temperaturas altas têm influência sobre a quantidade e a qualidade de trabalho que o ser humano pode realizar, também sobre a forma como ele pode ser feito.

O IBUTG registra o clima nos ambientes avaliados. Os dados obtidos por intermédio do IBUTG para os diversos ambientes de trabalho encontrados na propagação de plantas, são apresentados nas Figuras 1 e 2. De acordo com os dados analisados, verificou-se que os valores de IBUTG médio nas casas-de-vegetação com exaustores, apresentaram aumento crescente das 7 às $13 \mathrm{~h}$, sofrendo declínio após este horário. $\mathrm{O}$ IBUTG médio apresentou variação de $7,49^{\circ} \mathrm{C}$ entre as 7 e $13 \mathrm{~h}$, sendo que o IBUTG médio variava menos entre os dias frios e quentes, mantendo uma temperatura mais constante nessas casas.

Nas casas-de-vegetação sem exaustor, verificou-se comportamento do IBUTG médio semelhante ao do verificado nas casas com exaustor, sendo que, na primeira medição $(7 \mathrm{~h}) \mathrm{e}$ na última $(17 \mathrm{~h})$ o IBUTG médio era inferior nas casas sem exaustor. $\mathrm{O}$ pico máximo ocorreu às $13 \mathrm{~h}\left(28,93^{\circ} \mathrm{C}\right)$ verificandose um aclive até as $11 \mathrm{~h}$ e declive mais acentuado após as $15 \mathrm{~h}$, nas casas sem exaustor. Verificou-se, também, que o IBUTG é mais variável nas casas-de-vegetação sem exaustor, devido às

Tabela 1. Limites de tolerância para exposição ao calor, em conseqüência do índice de bulbo úmido - termômetro de globo (IBUTG)

\begin{tabular}{|c|c|c|c|c|c|}
\hline \multirow{2}{*}{$\begin{array}{l}\text { Consumo Energético } \\
\text { da Atividade }\left(\mathrm{kcal} \mathrm{h}^{-1}\right)\end{array}$} & \multicolumn{4}{|c|}{ Limites de Temperatura em ${ }^{\circ} \mathrm{C}$ para Regime de Trabalho de $1 \mathrm{~h}$} & \multirow{2}{*}{$\begin{array}{l}\text { Situação em que é } \\
\text { Proibido Trabalhar }\end{array}$} \\
\hline & $1 \mathrm{~h}$ de Trabalho & $\begin{array}{l}45 \text { min de Trabalho e } \\
15 \text { min de Descanso }\end{array}$ & $\begin{array}{l}30 \text { min de Trabalho e } \\
30 \text { min de Descanso }\end{array}$ & $\begin{array}{l}15 \text { min de Trabalho e } \\
45 \text { min de Descanso }\end{array}$ & \\
\hline Trabalho leve $<150$ & 30,0 & $30,1-30,6$ & $30,7-31,4$ & $31,5-32,2$ & $>32,2$ \\
\hline Moderado $150-300$ & até 26,7 & $26,8-28,0$ & $28,1-29,4$ & $29,5-31,1$ & $>31,1$ \\
\hline Pesado $>300$ & até 25,0 & $25,1-25,9$ & $26,0-27,9$ & $28,0-30,0$ & $>30,0$ \\
\hline
\end{tabular}
obtido (válido para homens e mulheres) 


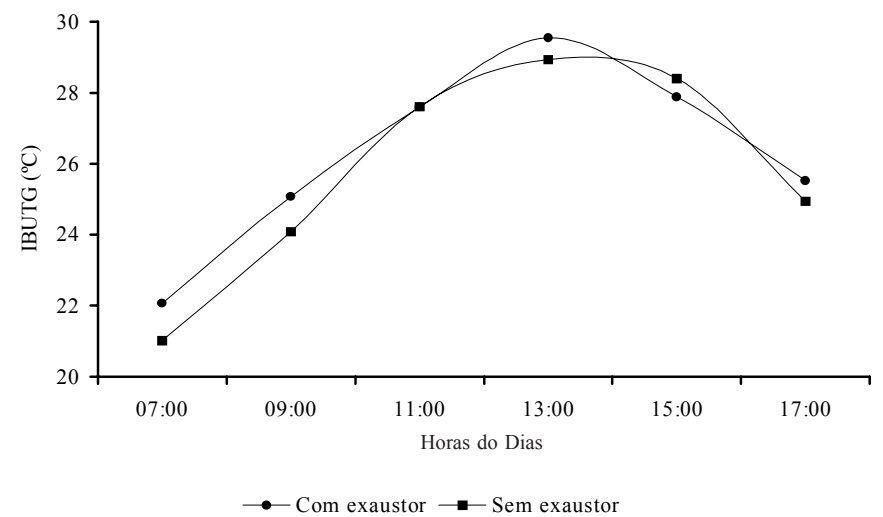

Figura 1. Variação do Índice de Bulbo Úmido - Termômetro de Globo (IBUTG) médio ao longo da jornada de trabalho, no período de 18 de setembro a 11 de outubro, nas casas-devegetação com e sem exaustor

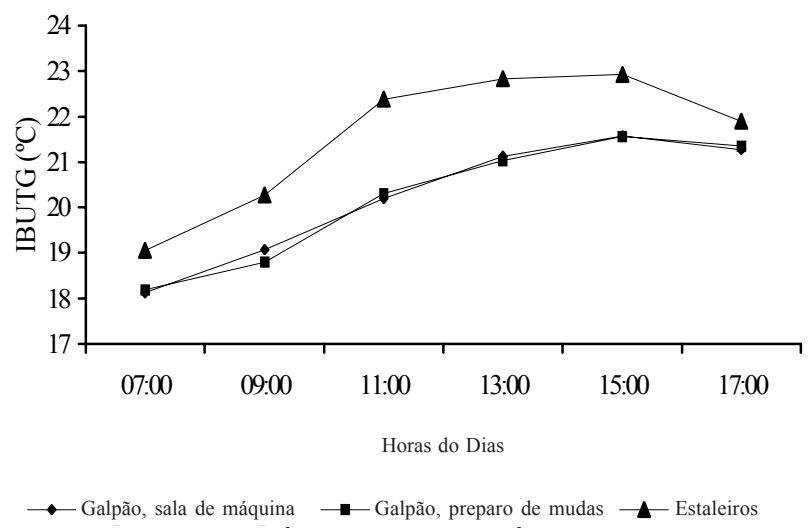

Figura 2. Variação do Índice de Bulbo Úmido - Termômetro de Globo (IBUTG) médio ao longo da jornada de trabalho no período de 18 de setembro a 11 de outubro, no galpão, sala de máquinas e preparo de mudas e estaleiros

aberturas laterais existentes nessas casas. Em dias frios, estas se tornam mais frias devido às aberturas laterais e, em dias mais quentes, se tornam mais quentes, por não terem exaustor para amenizar a temperatura; isto ocorre também durante a noite.

Nos estaleiros, galpões de enchimento de tubetes e preparo de mudas, o comportamento do IBUTG médio foi crescente até as $15 \mathrm{~h}$, com posterior declínio. Pelo fato dos trabalhos serem realizados sem nenhum tipo de proteção à radiação solar, os valores do IBUTG médio foram sempre maiores que nos galpões, como pode ser visto na Figura 2; já nos galpões, os valores foram semelhantes, não havendo grandes variações entre os resultados, sendo que estes estão abaixo dos limites estabelecidos pela NR 15 (Segurança e medicina do trabalho, 1998).

Quando o organismo está desenvolvendo uma atividade fora da zona de conforto térmico, o trabalhador pode sentir-se desconfortável, perdendo a motivação para o trabalho, mesmo que este não seja qualificado; a velocidade de reação das tarefas diminui; ocorre perda de precisão, perda de continuidade e diminuição da vigilância, o que torna o ambiente impróprio para o trabalho mental e, ainda, aumenta a incidência de acidentes, principalmente aqueles sem maior gravidade. A freqüência e a intensidade desses sintomas variam de trabalhador para trabalhador e, principalmente, com o tempo em que o indivíduo está exposto à agressão térmica. Em tais condições, deverá ser reduzido o tempo de permanência do indivíduo no local quente, o qual deverá ser alternado com um período de descanso (Couto, 1987).

Regime de trabalho: Analisando-se os valores encontrados do IBUTG médio nos diferentes ambientes na área de propagação de plantas, foi feita a interpretação para regime de trabalho e descanso, com base da Tabela 1. Desta forma, para as condições observadas nas casas-de-vegetação o trabalho é considerado moderado (metabolismo150 a $300 \mathrm{kcal} \mathrm{h}^{-1}$ ), conforme norma regulamentadora NR 15 (Segurança e medicina do trabalho, 1998), que contém as estimativas das taxas de metabolismo por tipo de atividade. O máximo IBUTG médio é de $26,7^{\circ} \mathrm{C}$ para trabalho moderado, também apresentado na referida norma. Como o máximo IBUTG médio entre as 9 e $17 \mathrm{~h}$, considerado crítico, foi de $28,94{ }^{\circ} \mathrm{C}$ para as casas sem exaustor e de $29,55^{\circ} \mathrm{C}$ para as casas com exaustor, verifica-se que o ciclo de trabalho desenvolvido pelos operadores na empresa é incompatível com a atividade física do trabalhador e com as condições térmicas dos ambientes analisados. Portanto, o limite de tolerância foi excedido, caracterizando uma situação em que o organismo está ganhando determinada quantidade de calor, em virtude do metabolismo e das condições ambientais desfavoráveis, tendo que utilizar a transpiração para perder este calor definindo, assim, sobrecarga térmica.

De acordo com o máximo IBUTG médio obtido, o regime de trabalho intermitente, segundo as normas legais vigentes, deve ser modificado para os trabalhadores sujeitos a esses ambientes de trabalho. Assim, para cada hora corrida de trabalho, de acordo com o limite de tolerância apresentado pela NR 15 (Tabela 1), eles podem trabalhar, no máximo, dentro das casas sem exaustores, 30 min e descansar no mínimo $30 \mathrm{~min}$. Nas casas com exaustor, os limites seriam de no máximo 15 min de trabalho e no mínimo 45 min de descanso. Para contornar esta situação, a empresa pode adotar as medidas citadas acima ou, então, manter os trabalhadores apenas até as $9 \mathrm{~h}$ nessas atividades e mudá-los para outras atividades em ambientes sem sobrecarga térmica.

Observou-se que, durante a jornada de $8,5 \mathrm{~h}$ de trabalho, o trabalhador direciona apenas 13 min para pausas, descansando apenas 5,4 e $3,6 \%$ do tempo que ele realmente necessita descansar, trabalhando nas casas com e sem exaustor, respectivamente.

Luminosidade: Nos ambientes internos, para tarefas com requisitos visuais normais, segundo a norma NBR 5413 $(A B N T, 1992)$ a iluminação geral para a área de trabalho deve estar entre 500 e 1000 lux. Conforme a Figura 3, verifica que o comportamento da iluminância, nas mesas de corte de macro, foi crescente até as $11 \mathrm{~h}$, quando atingiu o máximo 618,82 Lux, sofrendo declínio após este horário.

Nas bancadas de estaqueamento de micro, a variação da iluminância foi menor que nas mesas de macro, durante a jornada de trabalho, sendo que a iluminância nas primeiras horas do dia foi maior que nas últimas, devido à existência de 


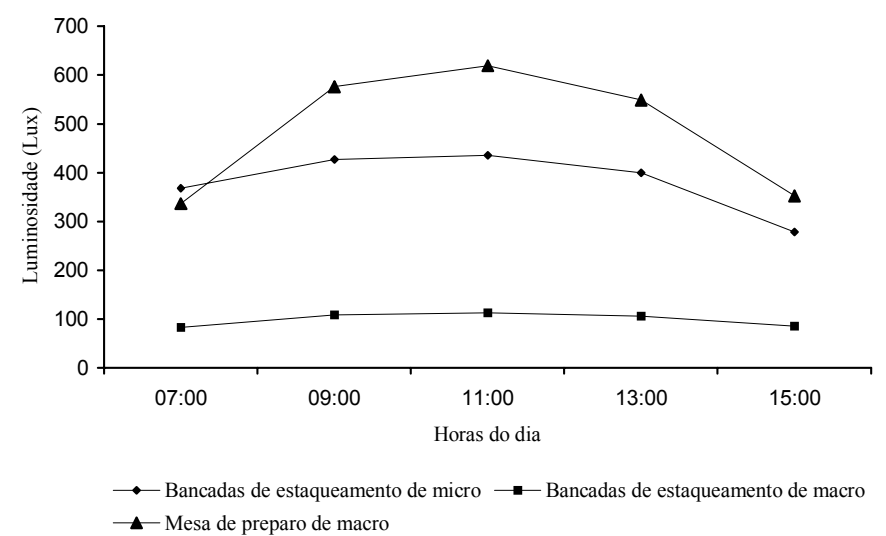

Figura 3. Variação da luminosidade média ao longo da jornada de trabalho, no galpão onde se encontravam as bancadas de estaqueamento de micro, macro e mesa de estaqueamento de macro

uma abertura lateral no sentido leste, favorecendo a iluminação natural pela manhã. O pico máximo de iluminância aconteceu às $11 \mathrm{~h}(435,64 \mathrm{Lux})$.

A situação mais crítica foi verificada na mesa de estaqueamento de macro e micro, sendo que, por receber pouca iluminação natural, a iluminância foi baixa e quase não sofreu variação durante toda a jornada de trabalho.

Os níveis de iluminância encontrados nas mesas de estaqueamento apresentaram-se deficientes, segundo as normas da ABNT (1992) durante a jornada de trabalho; já para a mesa de preparo das estacas, a deficiência só foi verificada antes das $9 \mathrm{~h}$ e depois das $13 \mathrm{~h}$, durante a jornada de trabalho.

Nos ambientes externos, os resultados de luminosidade foram crescentes até as $13 \mathrm{~h}$, quando atingiram valores máximos, sofrendo declínio mais acentuado até as 15 h (Fig. 4). Constatou-se, também, que os valores de iluminância dentro das casas-de-vegetação foram menores durante toda a jornada de trabalho, quando comparadas com os estaleiros, que recebiam luz direta.

Os rendimentos para tarefas com requisitos visuais normais, tendem a crescer a partir de 10 Lux, com o logaritmo do iluminamento até cerca 1000 Lux, enquanto a fadiga visual se reduz nessa faixa. A partir deste ponto, a fadiga visual começa a aumentar (Iida, 1992; Weerdmeester, 1993). Os trabalhadores

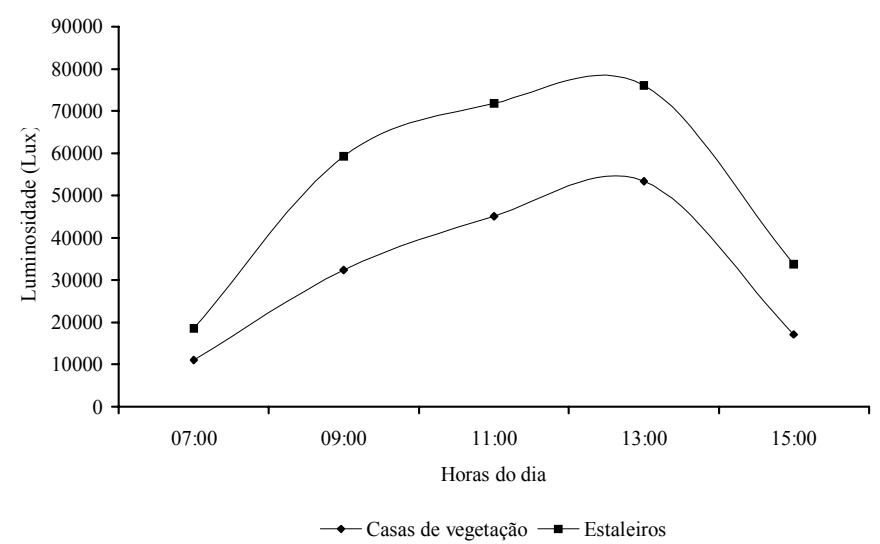

Figura 4. Variação da luminosidade média ao longo da jornada de trabalho, nos ambientes das casas-de-vegetação e estaleiros que atuam no corte de micro estão sujeitos a iluminância de até 76.000 Lux nas horas mais quentes do dia, o que pode levar a fadiga visual.

Ruído: O resultado das análises de ruído das diferentes atividades realizadas na propagação de plantas, encontra-se na Figura 5. Na fase de lavagem de tubetes ocorreu maior percentual de ruído durante a jornada de trabalho (123\%) sendo que a média diária foi $86,5 \mathrm{~dB}$, e o maior pico de ruído foi de 90 dB. As normas estabelecem que, acima de $85 \mathrm{~dB}$, os trabalhadores usem protetores auriculares ou, então, que seja reduzida a jornada de trabalho.

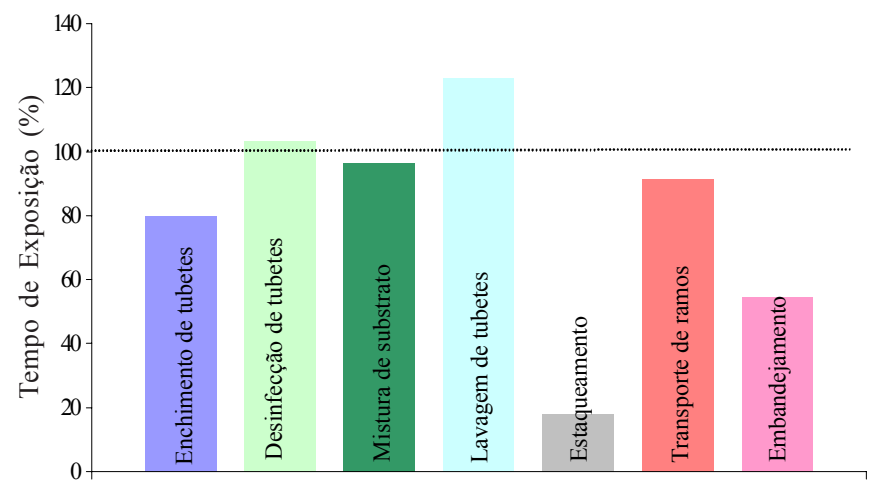

Figura 5. Dosagem de ruído durante a jornada de trabalho, em diversas atividades de propagação de plantas, em porcentagem

O ruído foi acima do limite recomendado pelas normas brasileiras também na desinfecção de tubetes, com uma dose diária média de 103,3\%, ou seja, uma média de 85,24 dB. O ruído variou de 73 a $90 \mathrm{~dB}$ durante a jornada de trabalho.

Nos outros ambientes da propagação de plantas, o nível de ruído ficou dentro dos limites estabelecidos pela norma. É importante lembrar que o ruído foi coletado durante toda a jornada de trabalho, inclusive no horário do almoço.

\section{CONCLUSÕES}

1. Os valores do índice de bulbo úmido termômetro de globo encontrados nas casas-de-vegetação, estão acima dos limites estipulados pela Norma Brasileira dos Manuais de Legislação Atlas, sobre Segurança e medicina do trabalho.

2. A luminosidade encontrada foi considerada insuficiente nos postos de trabalho das atividades de estaqueamento e de corte de macro de acordo com os níveis estabelecidos pela NBR 5413 da Associação Brasileira de Normas Técnicas.

3. Os níveis de ruído encontrados foram elevados, excedendo o nível de $85 \mathrm{~dB}$ nas atividades de lavagem de tubetes e de desinfecção de bandejas e tubetes, para uma jornada de trabalho de 8 h diárias.

\section{LITERATURA CITADA}

ABNT - Associação Brasileira de Normas Técnicas. NBR 5413 - Iluminância de interiores. Rio de Janeiro, 1992. 13p. 
Alves, J.U.; Fiedler, N.C.; Souza, A.P.; Machado, C.C. Estudo ergonômico do trabalho de limpeza de áreas com roçadoras costais. In: Simpósio Brasileiro sobre Colheita e Transporte Florestal, 3, 1997, Vitória. Anais... Vitória: SIF/DEF,1997. p.348-358.

Apud, E. Temas de ergonomia aplicados al aumento de la productividad de la mano de obra en cosecha forestal. In: Simpósio Brasileiro sobre Colheita e Transporte Florestal, 3, 1997, Vitória. Anais... Vitória: SIF/DEF, 1997. p.46-60.

Couto, H.A. Temas de saúde ocupacional - coletânea dos cadernos da Ergo. Belo Horizonte: Editora Ergo, 1987. 250p.

Couto, H.A. Ergonomia aplicada ao trabalho: o manual técnico da máquina humana. Belo Horizonte: Editora Ergo, v.l, 1995.353p.

Couto, H.A. Ergonomia aplicada ao trabalho: o manual técnico da máquina humana. Belo Horizonte: Editora Ergo, v.2, 1996. $383 p$.

Edholm, O.G. Biologia do trabalho. Porto: Inova, 1968. 258p.

Grandjean, E. Fitting the task to the man, an ergonomic approach. London: Taylor \& Francis, 1981.379p.
Iida, I. Ergonomia; projeto e produção. São Paulo: Edgard Blucher, 1990. 465p.

Iida, I.; Wierzzbicki, H.A.J. Ergonomia; notas de aula. São Paulo: EPUSP, 1978.282p

Máscia, F.L.; Santos, N. Análise ergonômica de um centro de controle. In: Seminário Brasileiro de Ergonomia, 4, 1989, Rio de Janeiro. Anais... Rio de Janeiro: ABERGO, 1989. p.69-76

Minette, L.J. Análise de fatores operacionais e ergonômicos na operação de corte florestal com motosserra. Viçosa: UFV, 1996. 211p. Tese Doutorado

Segurança e medicina do trabalho. $39^{\mathrm{a}}$ ed., v.16, São Paulo: Atlas, 1998. 584p. Manuais de Legislação Atlas

Souza, A.P. O uso de técnicas ergonômicas nas atividades de colheita de madeira. In: Congresso Florestal Panamericano, 1, Congresso Florestal Brasileiro, 7, 1993, Curitiba. Anais... Curitiba: SBS, SBEF, 1993. p.343-346.

Verdussen, R. Ergonomia: a racionalização humanizada do trabalho. Rio de Janeiro: Livro Técnico e Científico, 1978. $162 \mathrm{p}$. 